\title{
CHALLENGES OF VIRTUAL DESIGN AND CONSTRUCTION IMPLEMENTATION IN PUBLIC PROJECTS
}

\author{
Guillermo Prado Lujan ${ }^{1}$
}

\begin{abstract}
The Peruvian AEC industry has started implementing VDC and BIM in public projects due to recent regulations that state the progressive adoption of BIM (as a methodology) in public construction. Regardless of the benefits of these new approaches, some challenges to VDC implementation have emerged as a response to the resistance to change of the Peruvian AEC industry, which is stronger in the Peruvian public sector. The aim of this paper is to present the challenges found in the author's VDC implementation experience in a public project, as part of the third VDC Certificate Program in Lima lead by CIFE from Stanford University. These challenges will be identified based on a schema, constructed by the literature review. The results show that the main challenges found are the lack of commitment and the lack of collaboration between stakeholders. These results suggest the need to overcome this resistant-to-change environment by focusing on training programs and conducting capability assessments within public institutions before start implementing VDC, so more benefits will be achieved by the Peruvian public institutions.
\end{abstract}

\section{KEYWORDS}

Process, collaboration, commitment, challenges, VDC.

\section{INTRODUCTION}

The Peruvian Architecture, Engineering and Construction (AEC) industry has inherent problems to deal with, which affect both private sector projects and public sector projects. The drawbacks of the public sector projects are caused by poor management of the stages of planning and execution (design and construction), lack of government control, inherent fragmentation of the state contracting methods, financial obstacles, and incomplete basic engineering studies (Arnao, 2011). Therefore, the current problems are presented as project delivery delays, overbudget, and mistrustfulness from the stakeholders involved in this kind of projects.

Consequently, new project management approaches and tools have been introduced to the Peruvian AEC industry, Ghio (2001) concluded on the need to apply Lean Construction principles and 3D visualization tools to the infrastructure projects of Peru as a result of low productivity rates. Moreover, as a mean to improve the productivity and quality of the work, since 2012 selected Peruvian construction companies started to learn the Virtual Design and Construction (VDC) methodology, which is defined as "The use

Research Assistant, Construction Management \& Technology Research Group (GETEC), Pontifical Catholic University of Peru, guillermo.prado@ pucp.edu.pe, orcid.org/0000-0002-5325-1132 
of integrated multi-disciplinary performance model and design-construction projects to support explicit and public business objectives" (Kunz and Fischer, 2012).

On the public sector side, since 2018 several Peruvian laws have established the adoption of Building Information Modeling (BIM) to enhance the delivery of public infrastructure. In this context, Peruvian public institutions have started to implement VDC and BIM to trigger the AEC industry to the next level, which involves high levels of collaboration between stakeholders, use of technology, and constant control of the project production throughout metrics (Kunz and Fischer, 2009). Although, the idiosyncrasy presented in the Peruvian public sector generates a strong rejection to this new project management approach.

This research uses a literature review to identify the challenges presented during VDC implementations in the AEC industry, sets up a classification on these challenges, presents one case study as part of the third VDC certificate program in Lima, in which the author implemented VDC in a Peruvian public project. Then, the challenges found in this VDC implementation experience will be determined based on the classification identified in the literature. The research results will encourage the wider implementation of VDC in the Peruvian public sector by knowing the challenges that need to overcome before or during the VDC implementation process.

\section{LITERATURE REVIEW}

Virtual Design and Construction (VDC) is defined by Stanford University Center for Integrated Facility Engineering (CIFE) as "The use of integrated multi-disciplinary performance model and design-construction projects to support explicit and public business objectives" (Kunz and Fischer, 2009). These business objectives are both: client and project objectives; which provides an alignment between VDC and Lean Construction practices as it focuses on fulfilling the client's objectives. Khanzode et al. (2006) stated VDC as an enabler of Lean Project Delivery System (LPDS), as the tools, technologies, and methods of the VDC framework provide the best toolset to accomplish the ideals of the LPDS. In addition, VDC requires people to collaborate to reach measurable objectives they establish. It is integrative by nature and can be learned and mastered. Everything people do within the VDC framework allows them to integrate systems, processes, their organization and information so they can deliver highperforming buildings (Rischmoller et al., 2018).

Heymaker and Fischer (2001) found several technical challenges in the construction of the 4D-BIM models (which are part of VDC) including geometry and scheduling issues, and the linking of the geometry and the schedule. Gilligan and Kunz (2007) conducted a VDC Use Survey, which results showed a shift in the nature of limitations of VDC implementation: in the past difficulties were encountered more with technical issues or contractual terms between the parties involved in the project. But, by the year of the study, the limitations were more related to the lack of qualified people and the kind of training that needs to be provided. Kunz and Fischer (2012) present important limitations regarding the wide implementation of VDC in the AEC industry, which includes: lack of owner request or willingness to use VDC in its projects, the culture of minimizing cost in the AEC industry, lack of learning from experience and not-easy-to-use VDC modeling and analysis tools.

Khanzode et al. (2008) found challenges related to the VDC implementation in The Camino Medical Office Building (MOB) case study, focused on MEP coordination. These challenges include determining how to organize the project team and structure the 
coordination process to best utilize the VDC tools, how to set up the technical logistics, and how to perform the coordination in a Big Room. Teixeira (2014) found challenges in the VDC implementation of transport infrastructure projects: lack of infrastructure BIM software, the employment of an "open file format", the reduction of the opportunities for collaboration between stakeholders due to the design-bid-build delivery method, and the lack of involvement of contractors in the design process.

Several pieces of literature are focused on the limitations, barriers and challenges of BIM implementation in the AEC industry, which uses the term "VDC" as a synonym of "BIM". Regardless of the origin of the difference between these terms, which exceeds the limits of this study, the author considers relevant the outcomes of this literature due to the similarities between the implementation process of both VDC and BIM. Azhar et al. (2008) classified the industry implementation challenges on technical reasons and managerial reasons; Chan et al. (2014) focused on the designer's opinions on the barriers that affect the BIM or VDC implementation in the projects; Sun et al. (2017) proposed five factors that limitate the BIM or VDC implementation: technology, cost, management, personnel, and legal; and Criminale et al. (2017) classified the BIM or VDC implementation challenges by the association with project, organization or both.

As it was presented, previous research has shown the challenges found in various VDC implementation experiences based on case studies, usually, from the contractor or designer perspectives, and VDC implementation challenges at the industry level have been presented too. Despite the results shown in the previous studies, there is no study that addresses the VDC implementation challenges from the public client perspective and no study has analyzed the VDC implementation process in the Peruvian public sector. Therefore, the main objective of this research is to fill this research gap by identifying the challenges in the VDC implementation of Peruvian public projects.

\section{METHOD}

The aim of the study was to determine the challenges found in the VDC implementation of Peruvian public projects. Therefore, the research procedure consists of three steps:

The first step is collecting relevant studies in order to create a 'schema' for the challenges in VDC implementation. Two search conditions are used: the terms in the first search condition are "Virtual Design and Construction" or "VDC" or "BIM"; the terms in the second search condition are "challenge" or "barrier" or "obstacle" or "limitations". The material collected by the search is analyzed and classified based on a criterion, which defines the types of challenges in the VDC implementation.

The second step is studying the monthly reports of the Peruvian public project presented to the Stanford professors by the author throughout the conference calls. The measured metrics will be used to describe the outcomes of the VDC implementation in this Peruvian public project.

The third step is applying the same criteria used in the schema presented in step one to determine the challenges of the VDC implementation of the Peruvian public project analyzed in step two.

\section{RESULTS}

\section{SCHEMA FOR THE CHALLENGES IN VDC IMPLEMENTATION}

The implementation of VDC is beneficial to the AEC industry, but its methods are still undergoing theoretical development and in an industry that appropriately values risk 
mitigation, the changing theoretical foundation provides a handy and often an appropriate excuse to avoid the use of the methods (Kunz and Fischer, 2009). Table 1 shows a summary of the challenges found in the literature review based on the criterion that defines the type of challenge.

Table 1: Schema for the challenges of VDC implementation

\begin{tabular}{|c|c|c|}
\hline $\begin{array}{l}\text { Type of } \\
\text { challenge }\end{array}$ & Challenge & Reference \\
\hline \multirow[t]{4}{*}{$\begin{array}{l}\text { Legal issues } \\
\text { and } \\
\text { contracting } \\
\text { methods }\end{array}$} & $\begin{array}{l}\text { Define the scope of the implementation of VDC } \\
\text { while the project is being developed because it } \\
\text { was not defined in the requirements documents } \\
\text { (EIR, contracts, etc.) }\end{array}$ & $\begin{array}{l}\text { Teixeira } 2014 \text {; Kunz et } \\
\text { al. } 2012\end{array}$ \\
\hline & $\begin{array}{l}\text { Define the responsibility of licensed professionals } \\
\text { in this multi-contributors environment }\end{array}$ & Criminale et al. 2017 \\
\hline & $\begin{array}{l}\text { Require the participation of the general contractor } \\
\text { since the design stage of the project, despite the } \\
\text { contract does not allow it }\end{array}$ & $\begin{array}{l}\text { Khanzode, et al. 2008; } \\
\text { Sun et al. 2017; Teixeira } \\
2014\end{array}$ \\
\hline & $\begin{array}{l}\text { Use data from BIM models produced during the } \\
\text { VDC implementation to take decisions during the } \\
\text { project, despite the contract does not state it }\end{array}$ & $\begin{array}{l}\text { Criminale et al. 2017; } \\
\text { Chan } 2014\end{array}$ \\
\hline \multirow[t]{5}{*}{$\begin{array}{l}\text { Culture of the } \\
\text { organization }\end{array}$} & $\begin{array}{l}\text { Develop plans, protocols, standards, etc. before } \\
\text { starting the VDC implementation }\end{array}$ & $\begin{array}{l}\text { Criminale et al. 2017; } \\
\text { Chan 2014; Sun et al. } \\
\text { 2017; Azhar et al. } 2007\end{array}$ \\
\hline & $\begin{array}{c}\text { Promote and create the proper environment for } \\
\text { the involvement and collaboration between } \\
\text { stakeholders (subcontractors, end-users, etc.) in } \\
\text { the VDC implementation }\end{array}$ & $\begin{array}{l}\text { Khanzode, et al. 2008; } \\
\text { Criminale et al. 2017; } \\
\text { Sun et al. 2017; Azhar } \\
\text { et al. 2007; Teixeira } \\
\text { 2014; Kunz et al. } 2012\end{array}$ \\
\hline & $\begin{array}{l}\text { Involve all the departments of the institution in the } \\
\text { VDC implementation process lead by the general } \\
\text { managers of the institution }\end{array}$ & $\begin{array}{l}\text { Criminale et al. } 2017 \text {; } \\
\text { Sun et al. } 2017 \text {; Kunz et } \\
\text { al. } 2012\end{array}$ \\
\hline & $\begin{array}{c}\text { Consider the whole lifecycle of the project looking } \\
\text { for integration between its stages }\end{array}$ & $\begin{array}{l}\text { Khanzode, et al. 2008; } \\
\text { Sun et al. } 2017 \text {; Kunz et } \\
\text { al. } 2012\end{array}$ \\
\hline & $\begin{array}{c}\text { Promote the use of digital format documents and } \\
\text { data instead of continuing working with printed } \\
\text { documentation }\end{array}$ & Azhar et al. 2007 \\
\hline \multirow[t]{2}{*}{ People } & $\begin{array}{l}\text { Capacitate the professionals from the } \\
\text { stakeholders (client and providers) in a short } \\
\text { period of time to implement VDC in the project }\end{array}$ & $\begin{array}{l}\text { Criminale et al. } 2017 \text {; } \\
\text { Chan } 2014 ; \text { Sun et al. } \\
\text { 2017; Kunz et al. } 2012\end{array}$ \\
\hline & $\begin{array}{l}\text { Break the resistance to change from the } \\
\text { professionals involved in the project to implement } \\
\text { VDC }\end{array}$ & $\begin{array}{l}\text { Criminale et al. 2017; } \\
\text { Sun et al. 2017; Teixeira } \\
\text { 2014; Kunz et al. } 2012\end{array}$ \\
\hline
\end{tabular}

It is very important to notice that the criterion used for classifying the challenges does not include technology nor cost-related factors as the purpose of this schema for challenges in VDC implementation is to use it later to find the challenges in the VDC implementation of the Peruvian public project, which will show only the types of challenges presented in the schema of Table 1. 


\section{VDC Implementation in a Peruvian Public Project}

The Peruvian public project selected to implement VDC was the Centro de Emergenia Mujer (CEM), which consists of the design of a module inside a police building and the client was the Ministry of Interior (MININTER). The delivery method of this project was Design-Bid-Build (DBB), and the legal framework used involved the State Contracting Law of Peru and the National System of Multi-year Programming and Investment Management INVIERTE.PE. In this context, the design stage of this kind of project is divided into a specific number of "deliverables" (usually three) that also are considered as milestones for schedule and payment purposes; and is developed by two teams: "team A" that produces the design, and "team B" that assess the design produced by "team A". In the CEM project, "team A" was a design company and the "team B" was a team of architects and engineers (structural, electrical, plumbing and mechanical) formed by MININTER. The process and flow of one deliverable are shown in Figure 1.

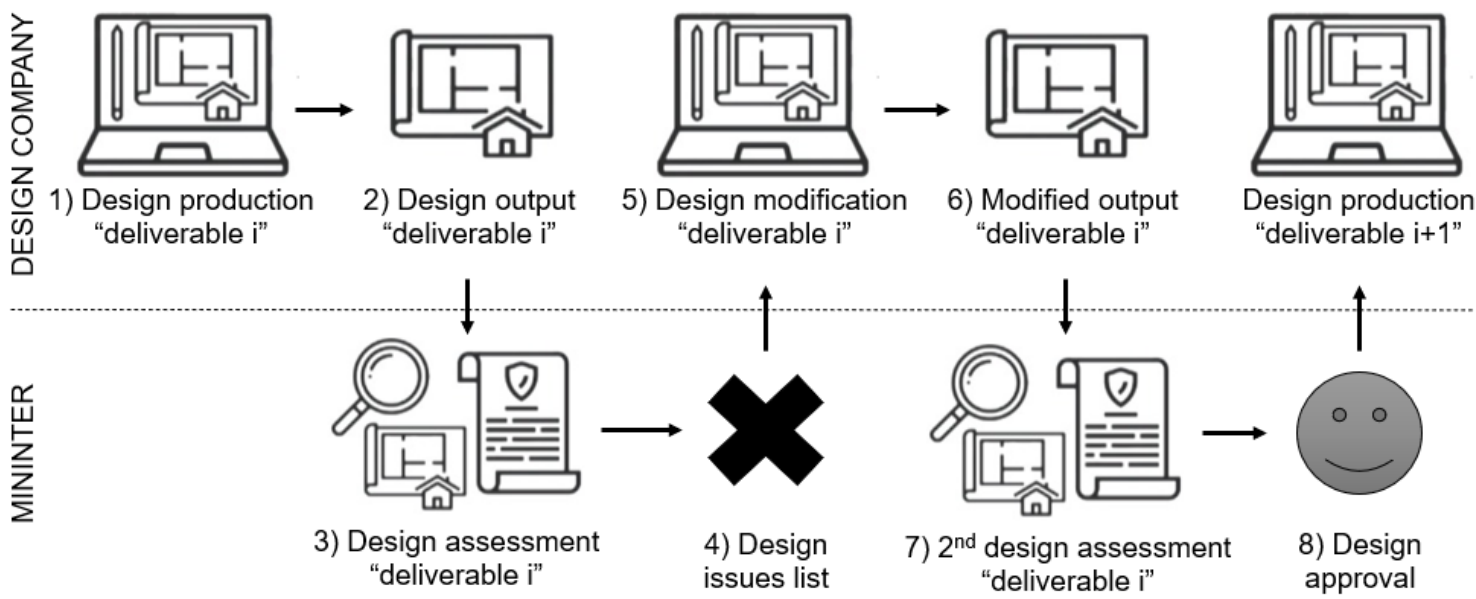

Figure 1: Design production and design assessment of one "deliverable"

The contractual documentation (Employer's information requirement, technical requirements, etc.) considered several BIM uses, Integrated Concurrent Engineering (ICE) sessions, and metrics to measure the production of the design company. MININTER conducted VDC training sessions with the members of the design company in order to share the expectations regarding the participation of this company in the project and the VDC implementation. However, each of the parties (MININTER and the design company) develop their work isolately due to the restrictions stated by the State Contracting Law, which does not allow the public institutions to participate directly in the project unless one contractual milestone is reached and the "deliverable" is presented formally (printed), as its shown in Figure 1. In addition, there was no internal VDC implementation in MININTER as the objective of implementing VDC was restricted to the CEM project.

The VDC implementation of this project was focused into finalize the design stage in four months. The production metrics measured were: PPC (Percent Plan Complete), assessment time per deliverable (production of review), \# of issues in the BIM models, \% of drawings produced by the BIM models, $\%$ of achieved goals during ICE sessions, and $\%$ of people (designers) involved in the solutions during ICE sessions. Unfortunately, the design of the project did not finalize as expected, but some of the mentioned metrics will provide the mean for finding the challenges in this VDC implementation.

During the monthly reports of the VDC implementation, the BIM metrics show these results: the "\# of issues in the BIM models' showed a significant decrement between each 
version of the BIM models, and nearly $60 \%$ of the design drawings were produced from the BIM models. Regarding the ICE metrics, nearly the $70 \%$ of the ICE sessions (15 out of 22) reached a $100 \%$ of achieved goals during ICE sessions; but no ICE session had a $100 \%$ in the metric '\% of people (designers) involved in the solutions'. The Project Production Management (PPM) metrics showed no good results during the last monthly report of the VDC implementation: the PPC reached almost $70 \%$ and the metric 'assessment time per deliverable (production of review)' indicates nearly 1 month periods for the assessment of one deliverable of design.

\section{ChaLlenges IN THE VDC IMPLEMENTATION}

\section{Challenges related to legal issues and contracting methods}

One of the most important challenge to overcome in the VDC implementation was to involve a general contractor in the project design, despite the CEM project was delivered by the DBB method, which does not allow the involvement of contractors in early stages of the project. It causes fragmentation through the development of the stages of the project: the design company will not be commited with the construction stage and, the expertise of the general contractor will not be considered in the design of the project, therefore any constructibility proposal cannot be considered due to the obligation to follow exactly the design output. Unfortunately, the State Constracting Law of Peru states restrictions for applying other delivery methods (Design-Build) and most of the public institutions have to use DBB, which does not allow to implement VDC as it should be: collaboratively.

Another challenge was to deal with the contractual conditions between MININTER and the members of the assessment team hired by this institution. Most of the architects and engineers hired by MININTER did not even have a contractual obligation of being located inside the MININTER offices, which caused delays in developing the assessment of the design and lack of feedback shared with the design company. Additionally, the conditions of these contracts allowed them to be hired by other institutions, which lead them to not being fully focused on the CEM project.

\section{Challenges related to the culture of the organizations}

The lack of a collaborative working approach inside the institutions is a big challenge experienced. The PPM metric 'assessment time per deliverable (production of review)' shown in the figure 2 helps to understand this challenge.

\section{PPM METRICS}

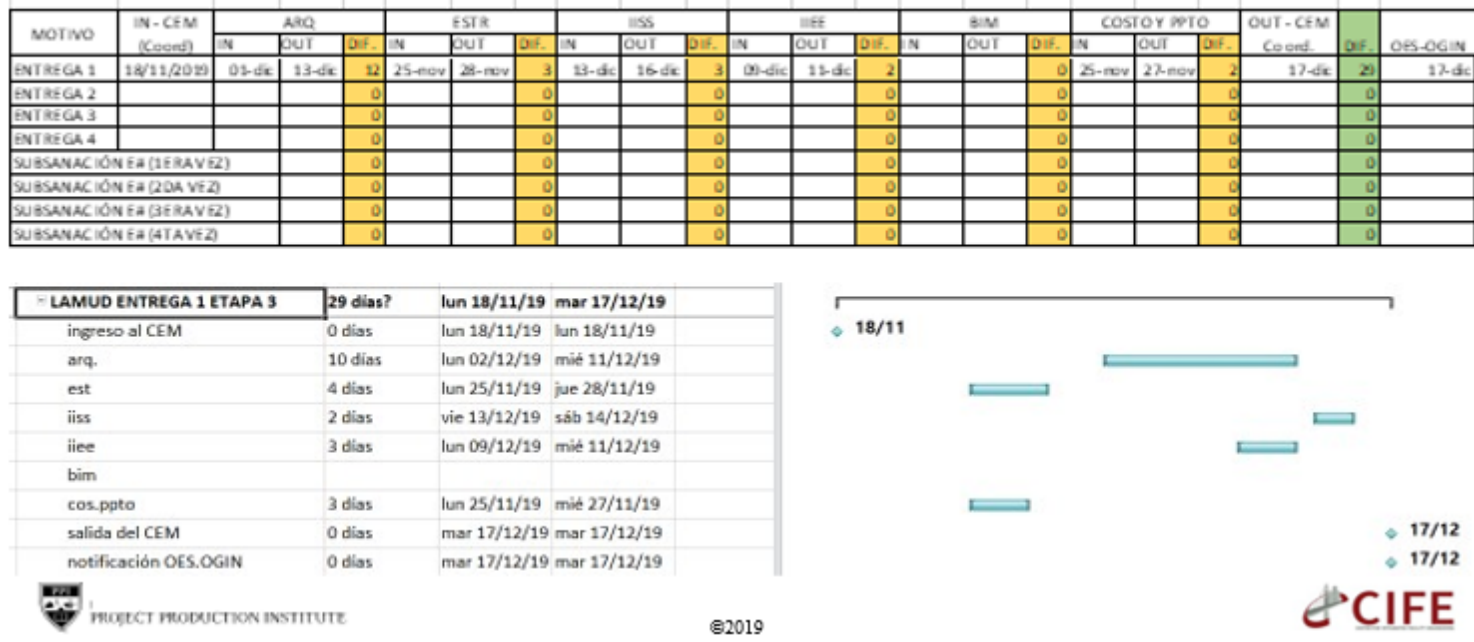

Figure 2: Isolated work between professionals 
Despite that the team members of MININTER can assess the design output all together concurrently, each architect and engineer took their time without any order and these activities were developed almost sequencially, as its shown in the Figure 2. This causes delays on providing feedback to the design company about the design output, and promotes no-concurrent work between stakeholders, which is inherently embedded in the culture of the organitzations involved in Peruvian public projects.

Another challenge was the lack of knowledge of the internal procedures and current status of MININTER, which lead us to produce process maps with almost all the departments of MININTER as its managerial documents did not show the information flow between the departments inside this institution. This situation caused that during the development of the CEM project, information and documents were lost as a result of no clear path to follow or workers with no idea of what to do with the documentation delivered. In addition, it caused delays in processing documentation and uncertainty regarding the current status of the project.

\section{Challenges related to the people}

The ICE metric '\% of people (designers) involved in the solutions' shown in figure 3 represents the lack of commitment of the designers (hired by the design company) to develop proper solutions to the technical issues addressed during the ICE sessions as no ICE session was fully attended by the designers. This situation caused that the solutions stated by the assistants of the ICE sessions could be changed later, as at least one discipline was not involved in that solution. In this context, the main challenge is to form a design team of committed people, that understand the project's objectives and the relevance of their participation in the implementation of VDC.

\section{ICE SESSIONS METRICS}

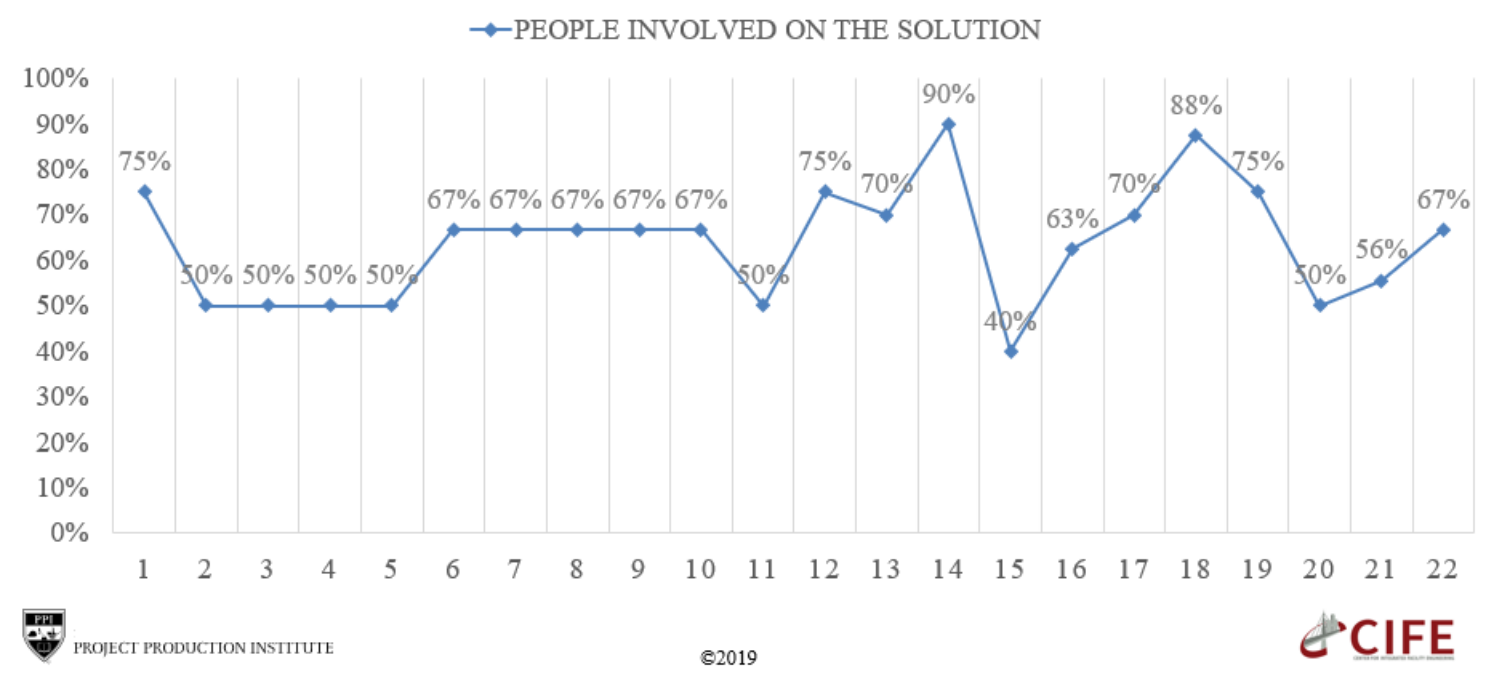

Figure 3: People involved on the solutions of the problems throughout ICE sessions

Also, the lack of VDC capabilities and misconception of this method from the team members of MININTER and from the design company affected negatively the project. The team members of the design company argued that they believed that BIM was a 3D model that can produce the drawings "rapidly" without any additional effort. In this context, the main challenge is to capacitate the team members of the public institution 
and require trained professionals in the project teams of the private providers, which has to be explicitly stated in the requirement documents during the bidding stage of the project.

\section{DISCUSSION}

The types of challenges defined in Table 1 provided criteria for organizing the data collected during the monthly reports (metrics) of the VDC implementation in order to use it for explaining the challenges found during this VDC experience. Despite that the metrics showed in this VDC experience were mainly focused on the design assessment process, the understanding of these metrics is believed to be benefitial for continuous improvement (Belsvik et al., 2019), as they gave insights about the limitations and challenges for implementing VDC inside MININTER.

The challenges related to legal issues and contracting methods (DBB) are clearly affecting the outcomes of the project and the origin of these challenges is the legal framework used in most Peruvian public projects. The State Contracting Law of Peru promotes fragmentation and states restrictions for using collaborative delivery methods that would be beneficial for these projects. In this context, this legal framework seems to be an uncontrollable factor for the project managers of Peruvian public institutions; therefore, there is no production metric to use in order to track the possible outcomes of the project. This lack of control happens when Peruvian public institutions contract: design providers, general contractors, and professionals (architects and engineers); which leads us to an uncertain situation regarding the impossibility to control it unless there is a structural change in the legal framework mentioned. Unfortunately, this is the most common contracting method (DBB) for infrastructure projects in Peru.

The challenges related to the culture of the organizations show that there is no worry about the current status of the projects of the Peruvian public institutions and the lack of a collaborative working approach between the team members of the stakeholders involved in the project. Also, this no-collaborative culture makes that public managers take the least risky and easiest decisions, and there is no concern for planning long-term goals. This situation might explain the reason for no developing managerial documents to understand the information flow and continuously waste time searching for the next step of one single repetitive internal process, nor making structural changes in the public institutions in order to be more efficient.

The challenges related to the people reveal no commitment of the people involved in the projects, which leads to delays in the project and other drawbacks too. This challenge has been studied previously, as all the team members of the project are required to be committed to the accomplishment of the objectives stated (Rischmoller et al., 2018) in the VDC implementation. Also, a central aspect to the VDC implementation has been to fully commit to those who want to change (Fosse et al., 2017), so to overcome this challenge a new team that believes in this approach may be established in order to implement VDC collaboratively. Regarding the misconception of the concepts related to VDC and BIM, the effort needed to work with BIM models properly had been underestimated by the design company and its use was not well planned, which introduced inefficiencies in their use (Mandujano et al., 2015). In this situation, is necessary to implement capacitation plans and capabilities assessment for the people involved in the project in order to reach its objectives. 


\section{CONCLUSIONS}

The VDC implementation experience in MININTER provided insights into the type of challenges that need to be overcome in order to accomplish the objective of the project. The types of challenges are related: the legal framework applied in this kind of project generates fragmentation throughout the development of the project and between the parties involved in it. The parties involved in the project lack collaboration, partially due to the legal framework and the inherent resistant-to-change culture of the Peruvian AEC industry, which generates a lack of commitment between the people involved in the project and misunderstanding of the concepts and implications of VDC. The metrics, an essential component of VDC, showed crucial information related to the production of the project, which provides a better understanding of the VDC implementation challenges presented in this research.

The outcomes of this study can be used to represent a wider and generalized problem of the Peruvian public institutions as the legal framework applied is the most commonly used in this kind of project. The implementation of VDC makes transparent inherent problems related to the management of Peruvian public projects, as the production metrics provide data to control times and demonstrate that the implementation of VDC has to overcome several challenges, not only in the project and people level, but in the organizational and legal framework level too. Moreover, the problems presented in this study are hidden in the Peruvian public institutions, or maybe the public managers ignore their existence, but by implementing VDC they can be displayed in order to propose countermeasures against these problems.

Regardless of all the challenges stated in this paper, the enhancement of the AEC industry through VDC is imminent. In consequence, the public institutions should start with the development of a capability assessment and find an implementation plan that enables collaborative implementation of VDC in order to reach their respective goals.

\section{ACKNOWLEDGMENTS}

The author thanks the participants of the third VDC Certificate Program in Lima and the members of MININTER, whom helped him to understand the VDC challenges presented.

\section{REFERENCES}

Arnao Rondán, R. (2011). La eficiencia en la gestión pública: "El caso de la gestión de inversión pública local en el Perú" [The efficiency in the public management: "The case study of local public investment in Peru"]. Lima: Serie de investigaciones 6: Universidad Católica Sedes Sapientae. [In Spanish].

Azhar, S., Hein, M., \& Sketo, B. (2008). Building Information Modeling (BIM): Benefits, Risks and Challenges. Proc., 44th Associated Schools of Construction National Conference, Auburn, AL.

Belsvik, M.R., Lædre, O., and Hjelseth E. (2019). “Metrics In VDC Projects.” In: Proc. 27th Annual Conference of the International Group for Lean Construction (IGLC), Pasquire C. and Hamzeh F.R. (ed.), Dublin, Ireland, pp. 1129-1140. DOI: https://doi.org/10.24928/2019/0167. Available at: IGLC.net.

Chan, C. T. W. (2014). Barriers of Implementing BIM in Construction Industry from the Designers' Perspective: A Hong Kong Experience. ISSN Journal of System and Management Sciences Journal of System and Management Sciences, 4(2), 1816-6075. 
Criminale, A., and Langar, S. (2017). Challenges with BIM implementation: a review of literature. In Proceedings of 53rd Associated School of Construction International Conference, Seattle, WA, April, 329-335.

Fosse, R., Ballard, G., and Fischer, M. (2017). "Virtual Design and Construction: Aligning BIM and Lean in practice". In: LC3 2017 Volume II - Proceedings of the 25th Annual Conference of the International Group for Lean Construction (IGLC), Walsh, K., Sacks, R., Brilakis, I. (eds.), Heraklion, Greece (pp. 499-506). DOI: https://doi.org/10.24928/2017/0159. Available at: IGLC.net.

Ghio Castillo, V. (2001). Productividad en obras de construcción: Diagnóstico, crítica y propuesta [Productivity in construction works: diagnosis, criticism and proposal]. Lima. Pontificia Universidad Católica del Perú, Fondo Editorial, 2001. [In Spanish].

Gilligan, B. and Kunz, J. (2007). VDC use in 2007: Significant use, dramatic growth, and apparent business opportunity. CIFE Working Paper 103. Stanford, CA: Center for Integrated Facility Engineering (CIFE), Stanford University.

Haymaker, J., and Fischer, M. (2001). Challenges and Benefits of 4D Modeling on the Walt Disney Concert Hall Project. CIFE Working Paper 64. Stanford, CA: Center for Integrated Facility Engineering (CIFE), Stanford University.

Khanzode, A., Fischer, M., Reed, D., and Ballard, G. (2006). A Guide to Applying the Principles of Virtual Design \& Construction (VDC) to the Lean Project Delivery Process. CIFE Working Paper, 93. Stanford, CA: Center for Integrated Facility Engineering (CIFE), Stanford University.

Khanzode A., Fischer M., Reed D. (2008). "Benefits and Lessons Learned of Implementing Building Virtual Design and Construction (VDC) Technologies For Coordination Of Mechanical, Electrical, and Plumbing (MEP) Systems On A Large Healthcare Project", ITcon, 13, 324 - 342.

Kunz, J., and Fischer, M. (2009). Virtual Design and Construction: Themes, Case Studies and Implementation Suggestions. CIFE Working Paper 97 (Version10). Stanford, CA: Center for Integrated Facility Engineering (CIFE), Stanford University.

Kunz, J., \& Fischer, M. (2012). Virtual Design and Construction: Themes, Case Studies and Implementation Suggestions. CIFE Working Paper 97 (Version14). Stanford, CA: Center for Integrated Facility Engineering (CIFE), Stanford University.

Mandujano, M.G., Alarcón, L.F., Kunz, J., and Mourgues, C. (2015). Use of Virtual Design and Construction, and its Inefficiencies, From a Lean Construction Perspective. In: Proc. 23rd Annual Conference of the International. Group for Lean Construction (IGLC). Perth, Australia, July 29-31, pp. 836-845, available at IGLC.net.

Prado, G. (2019) VDC December 2019, Report VDC Certificate Program.

Rischmoller, L., Reed, D., Khanzode, A., and Fischer, M.(2018). "Integration Enabled by Virtual Design and Construction as a Lean Implementation Strategy" In: Proc. 26th Annual Conference of the International. Group for Lean Construction (IGLC), González, V.A. (ed.), Chennai, India, pp. 240-249. doi.org/10.24928/2018/0521.

Sun, C., Jiang, S., Skibniewski, M. J., Man, Q., \& Shen, L. (2017). A literature review of the factors limiting the application of BIM in the construction industry. Technological and Economic Development of Economy, 23(5), 764-779. doi.org/10.3846/20294913.2015.1087071

Teixeira, H. (2014). VDC implementation in transport infrastructure projects. Master's thesis. Department of civil and transport engineering, Norwegian University of Science and Technology. 